PHILOSOPHICAL
TRANSACTIONS
$\begin{aligned} & \text { THE ROYAL Phil. Trans. R. Soc. A }(2009) \mathbf{3 6 7}, 3941-3963 \\ & \text { SOCIETY }\end{aligned}$

\title{
Environmental fate of phenolic endocrine disruptors: field and laboratory studies
}

\author{
By Walter Giger*, Frédéric L. P. Gabriel, Niels Jonkers, \\ Felix E. Wettstein and Hans-Peter E. Kohler \\ Eawag, Swiss Federal Institute of Aquatic Science and Technology, \\ 8600 Dübendorf, Switzerland
}

\begin{abstract}
Alkylphenolic compounds derived from microbial degradation of non-ionic surfactants became a major focus of environmental research in the early 1980s. More toxic than the parent compounds and weakly oestrogenic, certain metabolites of nonylphenol polyethoxylate (NP $n \mathrm{EO}$ ) surfactants, especially nonylphenol (NP), raised sustained concern over the risk they pose to the environment and triggered legal measures as well as partly voluntary actions by the manufacturing industry. Continuous progress in the development of analytical techniques is crucial to understand how these alkylphenolic compounds behave in wastewater treatment, the aquatic environment and in laboratory experiments. Measured concentrations and mass flows of phenolic endocrine disruptors, particularly nonylphenolic compounds, bisphenol A and parabens in municipal wastewater effluents and in the Glatt River, Switzerland, show that rain events leading to discharges of untreated wastewater into rivers have a great impact on the riverine mass flows of contaminants. Biotransformation experiments in our laboratory with nonylphenoxyacetic acid and individual NP isomers enabled the elucidation of degradation pathways of these compounds. The finding that nonylphenoxyacetic acid is metabolized via NP further underscores the role of NP as the most relevant metabolite in the degradation of $\mathrm{NP} n \mathrm{EO}$. Several Sphingomonadaceae bacterial strains were found to degrade $\alpha$-quaternary 4 -NP isomers by an ipso-substitution mechanism, and to use only the aromatic part of the molecule. These reactions turned out to be isomer specific, meaning that rate and extent of transformation depend on constitution, and possibly also on the absolute configuration of the alkyl side chain of a specific isomer. The observation that NP isomers with distinct oestrogenic activities are differentially degraded has significant implications for risk assessment.
\end{abstract}

Keywords: nonylphenol; nonylphenoxyacetic acid; biotransformation; oestrogenic activity; wastewater; rivers

\section{Introduction and retrospect}

The history of environmental chemical pollutants is dominated by several chemical compound classes of different characteristics such as petroleum hydrocarbons, polycyclic aromatic hydrocarbons, synthetic surfactants, polychlorinated *Author for correspondence (giger@eawag.ch).

One contribution of 12 to a Theme Issue 'Emerging chemical contaminants in water and wastewater'. 
<smiles>CCC(C)(CCC(C)C)c1ccc(O)cc1</smiles>

NP<smiles>CCC(C)(CCC(C)C)c1ccc(OCCOCCO)cc1</smiles>
$\mathrm{NP} n \mathrm{EO}$<smiles>CCC(C)(CCC(C)C)c1ccc(OCCOCC(C)C(=O)O)cc1</smiles>

nonylphenol ((poly)ethoxy)acetic acids (NPnEC)<smiles>CCC(C)(CCC(C)C(=O)O)c1ccc(OCCOCC(C)C(=O)O)cc1</smiles>

carboxyoctylphenol ((poly)ethoxy)acetic acids (CAPnEC)<smiles>CC(C)(C)CC(C)(C)c1ccc(O)cc1</smiles>

OP<smiles>CC(C)(c1ccc(O)cc1)c1ccc(O)cc1</smiles>

BPA<smiles>Oc1ccccc1-c1ccccc1</smiles>

ortho-phenylphenol (PhP)

$$
\begin{gathered}
\mathrm{R}= \\
\mathrm{C}_{4} \mathrm{H}_{9}, \mathrm{CH}_{2} \mathrm{C}_{6} \mathrm{H}_{6} \mathrm{H}_{5}, \mathrm{C}_{3} \mathrm{H}_{7},
\end{gathered}
$$

Figure 1. Structures and acronyms of nonylphenolic compounds and phenolic endocrine disruptors. Note that in the case of $\mathrm{NP}$ the para-substituted isomer, $\mathrm{NP}_{112}$, is drawn as an example. In the case of OP, the only isomer contained in commercial surfactants is drawn.

insecticides, polychlorinated biphenyls, polychlorinated dibenzodioxins, arsenic, heavy metals, tin organics, etc. Among the technically produced surfactants, nonylphenol polyethoxylates ( $\mathrm{NP} n \mathrm{EO})$ and their metabolites became a major focus of environmental research when it became evident in the early 1980s that alkylphenolic compounds derived from non-ionic surfactants of the alkylphenol polyethoxylate type are significant environmental contaminants. In figure 1, structural formulae and acronyms for the prevalent nonylphenolic substances are presented. Besides nonylphenol (NP) and octylphenol (OP), we discuss here some other weakly oestrogenic phenolic substances, among them bisphenol A (BPA) and parabens (figure 1). 
Environmentally relevant nonylphenolic compounds, such as NP, NP monoethoxylate (NP1EO), NP diethoxylate (NP2EO), nonylphenoxyacetic acid (NP1EC) and nonylphenoxyethoxyacetic acid (NP2EC), do not appear in the environment because of direct use in chemical products, but they are formed in the course of the biological degradation of $\mathrm{NP} n \mathrm{EO}$. These chemicals are commercially important non-ionic surfactants still used in the USA and in many other countries as products for industrial, agricultural, household and institutional applications. However, $\mathrm{NP} n \mathrm{EO}$ surfactants are banned for water relevant uses in the EU and in Switzerland. NP, NP1EO and NP2EO are known weakly endocrine disrupting chemicals (EDCs; Sumpter \& Johnson 2008; Martin \& Voulvoulis 2009). Reports on the environmental occurrence of polar organic water pollutants indicate that the $\mathrm{NP} n \mathrm{EO}$ metabolite NP1EC is among the most abundant contaminants in European rivers (Reemtsma et al. 2006; Jonkers et al. 2009; Loos et al. 2009).

Table 1 lists milestones in the history of $\mathrm{NP} n \mathrm{EO}$ surfactants as synthetic technical products and of nonylphenolic compounds as environmental contaminants. The increase in knowledge on the environmental occurrence and fate of nonylphenolic compounds was strongly promoted by the evolution in analytical methodology. Regarding an environmental risk assessment, it became apparent that the nonylphenolic metabolites of $\mathrm{NP} n \mathrm{EO}$ surfactants, in particular NP, were more toxic than the parent substances (McLeese et al. 1980; Comber et al. 1993). In the early 1990s, several researchers discovered the significant oestrogenic effects of NP and other NP $n$ EO metabolites (Soto et al. 1991; Jobling \& Sumpter 1993), which greatly raised the concern and scientific interest in nonylphenolic compounds as environmental contaminants (for reviews, see Soares et al. (2008), Sumpter \& Johnson (2008) and Martin \& Voulvoulis (2009)).

Detailed risk assessments have been performed for some of the phenolic chemicals discussed in this article, particularly for NP and BPA. In the NP case, this has led to legal restrictions of the $\mathrm{NP} n \mathrm{EO}$ use in many countries. In the European Water Framework Directive, NP is considered a Priority Substance and Environmental Quality Standards for surface waters have been set at 0.3 and $2.0 \mathrm{\mu gl}^{-1}$ for annual average and maximum allowable concentrations, respectively.

The research on nonylphenolic substances at Eawag, the Swiss Federal Institute of Aquatic Science and Technology, started in the early 1980s with the identification and quantitative measurement of the $\mathrm{NP} n \mathrm{EO}$ metabolites NP, NP1EO and NP2EO in treated municipal wastewaters (Giger et al. 1981; Stephanou \& Giger 1982) using capillary gas chromatography (GC) with flame ionization (FID) and mass spectrometric (MS) detection. Subsequently, accumulation of the toxic NP in digested sewage sludge was observed (Giger et al. 1984). Municipal mechanical-biological wastewater treatment plants (WWTPs) were then investigated using a mass flow analysis or mass balance approach (Brunner et al. 1988; Ahel et al. 1994a). During his PhD studies, Ahel (1987) accomplished a series of substantial projects at Eawag and at the Rudjer Boscovic Institute in Zagreb that formed the basis for our current understanding of the environmental fate of these compounds (for references, see table 1). New analytical techniques based on liquid chromatography (LC) were developed, process-oriented field studies in WWTPs and in rivers carried out and laboratory experiments performed. 
Table 1. Milestones in the history of nonylphenolic substances as environmental contaminants.

technological product development

1933 invention of polyethoxylate surfactants by C. Schoeller, BASF, Germany

1937 switch from vegetable oil based aliphatic raw material to coal derived phenolics because of supply problems

analytical methods

1960 collective determination of non-ionic surfactants

1967 thin-layer chromatography of non-ionic surfactants

1980 GC/FID, GC/MS

1984 LC/UV absorption, LC/UV fluorescence

2001 LC/MS, LC/MSMS

1995 high-resolution GC for NPs

2009 comprehensive two-dimensional gas chromatography/time-of-flight mass spectrometry (GCGC/TOFMS)

environmental occurrence

1981 NP, NP1EO and NP2EO in treated municipal wastewater

1984 NP in digested sewage sludge

$1985 \mathrm{NP} n \mathrm{EC}$ in wastewater

1985 nonylphenolic compounds in rivers

1985 nonylphenolic compounds in groundwater

$2000 \mathrm{CAP} n \mathrm{EC}$ in wastewater

Patterson et al. (1967)

Giger et al. (1981),

Stephanou \& Giger (1982)

Ahel (1987), Ahel \& Giger $(1985 a, b)$

Jonkers et al. (2001, 2009),

Ferguson et al. (2001)

Wheeler et al. (1997)

Eganhouse et al. (submitted)

environmental fate and behaviour

1968 studies on non-ionic detergent degradation

1973 biodegradability of $\mathrm{NP} n \mathrm{EO}$

1988 mass flows in wastewater treatment

1987 physico-chemical behaviour

2005 biotransformation of individual NP isomers

Giger et al. (1981),

Stephanou \& Giger (1982)

Giger et al. (1984)

Ahel (1987), Ahel et al. (1987,

$1994 a)$, Field \& Reed (2001)

Ahel (1987), Ahel et al. (1994b)

Ahel (1987), Ahel et al. (1996)

Di Corcia et al. $(1998,2000)$

Patterson et al. $(1968,1970)$

Rudling \& Solyom (1974)

Brunner et al. (1988),

Ahel et al. (1994a)

Ahel (1987)

Gabriel et al. (2005a,b, $2007 a, b, 2008)$,

Kohler et al. (2008)

environmental effects and risk assessment

1980 lethality of Aminocarb components

McLeese et al. (1980)

1993 effects of NP on Daphnia magna

Comber et al. (1993)

1991 oestrogenic activity of NP

Soto et al. (1991)

1993 oestrogenic activity of NP $n$ EO metabolites

Jobling \& Sumpter (1993)

2003 EU risk assessment for NP

legal measures

1986 partial ban of $\mathrm{NP} n \mathrm{EO}$ surfactants in Switzerland

1987 voluntary agreement in Germany

2003 comprehensive ban of $\mathrm{NP} n \mathrm{EO}$ surfactants in the EU

2007 environmental quality standard for NP within the EU Water Framework Directive

miscellaneous

2001 synthesis of individual NP isomers

Boehme et al (submitted)

2006 proposal of a numbering system for NP isomers

Guenther et al. (2006) 
Table 1 includes an overview of the studies that have been performed since the early 1980s at Eawag, where the most recent research phase was based on two projects that were part of the Swiss National Research Programme on 'Endocrine Disruptors: Relevance to Humans, Animals and Ecosystems'. The bulk of this article summarizes the results of these projects. Analytical field studies were carried out using liquid chromatography coupled either to fluorescence or to mass spectrometric detection (Wettstein 2004; Voutsa et al. 2006; Jonkers et al. 2009). A relatively large project focused on a comprehensive river basin study in the Glatt valley in Switzerland encompassing WWTP effluents and rivers. A second focus was on biotransformation studies in the laboratory, which profited enormously from the availability of NP1EC (Wettstein 2004) and of individual NP isomers (Gabriel et al. $2005 a, b, 2007 a, b$, 2008; Kohler et al. 2008). We present investigations on the biotransformation of nonylphenoxyacetic acid and individual NP isomers under laboratory conditions. Careful analysis of the results enabled us to significantly enhance the knowledge on the corresponding biotransformation pathways.

\section{Field studies on occurrence and behaviour}

\section{(a) Analytical methods}

During nearly four decades, the prevailing coverage in analytical environmental chemistry was on volatile and semivolatile non-polar/lipophilic contaminants, because GC as the predominantly employed analytical technique provided excellent separations for these types of pollutants. However, very polar and amphiphilic contaminants (e.g. anionic, non-ionic and cationic surfactants) could only be determined by GC after derivatization or transformation of the analytes into more volatile species. Amphiphilic substances (surfactants, surfaceactive agents) were for a long time determined almost exclusively by collective parameters without separation into individual components. The more volatile NP, NP1EO and NP2EO could still be reliably determined by GC (Giger et al. 1981; Stephanou \& Giger 1982). The introduction of high-performance liquid chromatography (HPLC or LC) enabled the specific determination of several surfactant classes including the alkylphenolic compounds by ultraviolet absorption or fluorescence detection (Ahel 1987; Ahel \& Giger 1985a,b; Ahel et al. 1987, 2000a; Marcomini \& Giger 1987).

With the development of new ionization techniques such as electrospray ionization and atmospheric pressure chemical ionization, liquid chromatography directly coupled to mass spectrometry (LC/MS) has become since the mid-1990s a routinely applicable and robust method. LC/MS allows a far better coverage of polar/hydrophilic and amphiphilic contaminants (Giger 2009). Furthermore, the extremely high selectivity and sensitivity of multiple reaction monitoring techniques in tandem/multi-stage quadrupole and ion-trap mass spectrometry (MSMS) enable the analyses of trace constituents of complex mixtures. Typical examples of LC/MSMS application to alkylphenolic substances and other surfactants were published by Ferguson et al. (2001), Jonkers et al. (2001, 2009), Gonzalez et al. (2007) and Loos et al. (2007, 2008). 


\section{(b) Municipal wastewater, wastewater treatment and rivers}

Since the pioneering reports on nonylphenolic compounds in municipal wastewater and wastewater treatment effluents by the Eawag group (table 1), many authors have published original reports (e.g. Ferguson et al. 2001; Jonkers et al. 2001) and reviews on this topic (e.g. Soares et al. 2008; Staples et al. 2008; Martin \& Voulvoulis 2009). Ahel et al. (2000b) revisited the earlier Eawag findings from the 1980s and documented the effects of risk reduction measures introduced in 1986 and of the improved performance of wastewater treatment. The situation is complicated, because we have to consider a complex technical product with mixtures of polyethoxymers and isomers as well as several metabolites with shorter polyethoxy substituents and possibly one or two carboxylate groups, $\mathrm{NP} n \mathrm{EC}$ and CAP $n \mathrm{EC}$, respectively (figure 1 ).

It is generally accepted that the carboxylated metabolites are at least partly formed during activated sludge treatment in the WWTPs, which may lead to rather high levels in secondary effluents and subsequently in receiving ambient waters (Ahel et al. 1987; Di Corcia et al. 2000). This particular situation is the reason why in a more recent investigation at Eawag, Wettstein (2004) studied NP $n$ EOs and their respective metabolites with an emphasis on NP1EC. That study was performed in two parallel treatment trains at the wastewater treatment facility in Kloten/Opfikon, Switzerland: (i) the full-scale conventional wastewater treatment train using activated sludge treatment and a sand filter and (ii) a pilotscale membrane bioreactor. Only small concentration differences were observed among effluent samples originating from either treatment train. NP, NP1EO and NP2EO elimination rates ranged from 82 per cent to 96 per cent. The NP1EC elimination rate reached 46 per cent in the membrane reactor and 58 per cent in the conventional plant. Metabolite concentrations decreased by up to 75 per cent during passage of the wastewater through the sand filter. Conventional wastewater treatment without sand filter achieved a lower elimination rate compared to that of the membrane plant. These data indicate that a relatively simple additional treatment like a sand filter provides an increased bioelimination of contaminants such as NP1EC.

The study by Jonkers et al. (2009) focused on the occurrence and behaviour of several phenolic EDCs including alkylphenolic compounds, BPA, phenylphenol $(\mathrm{PhP})$ and parabens in municipal wastewaters and in the River Glatt near Zurich. A strong emphasis was put on discussing not only concentrations but also mass flows and comparing measured river data with the results of calculations based on a mass balance approach.

Table 2 shows the concentrations for the investigated EDCs. Both WWTP influents and effluents as well as river water were dominated by the alkylphenolic compounds, which were present at several micrograms per litre in WWTP influents, several 100 to $1000 \mathrm{ngl}^{-1}$ in WWTP effluents and up to several $100 \mathrm{ng}^{-1}$ in the Glatt. OP, BPA and PhP concentrations in river water were a few nanograms per litre, whereas WWTP influent levels were several $100 \mathrm{ng} \mathrm{l}^{-1}$ for BPA and PhP and a few tens of nanograms per litre for OP. As a result of the phasing-out of alkylphenol polyethoxylates since the late 1980s and improvements in the performance of the municipal wastewater treatment, concentrations of alkylphenolic compounds were more than an order of magnitude lower than the values found in the River Glatt in 1984 (Ahel 1987; Ahel et al. 1994b). 
Table 2. EDC concentrations $\left(\mathrm{ng}^{-1}\right)$ in WWTP influents and effluents as well as in the Glatt River (adapted from Jonkers et al. 2009).

\begin{tabular}{|c|c|c|c|c|c|c|c|c|c|c|}
\hline & \multicolumn{3}{|c|}{ WWTP influent } & \multicolumn{3}{|c|}{ WWTP effluent } & \multirow{2}{*}{$\begin{array}{l}\text { average } \\
\text { removal in } \\
\text { WWTP }(\%)\end{array}$} & \multicolumn{3}{|c|}{ Glatt River } \\
\hline & median & $\min$. & $\max$. & median & $\min$. & $\max$. & & median & $\min$ & $\max$ \\
\hline NP1EO & 1140 & 201 & 7030 & 34 & 15 & 139 & 95.1 & 18 & $<7.3$ & 42 \\
\hline NP2EO & 1890 & 596 & 4060 & 40 & 16 & 335 & 97.0 & 9.4 & 2.8 & 110 \\
\hline NP2-7EO & 6820 & 1450 & 21700 & 119 & 15 & 579 & 97.7 & 71 & $<0.9$ & 624 \\
\hline NP8-10EO & 257 & 14 & 1740 & 0.6 & $<0.9$ & 16 & 99.3 & 0.8 & $<0.9$ & 16 \\
\hline NP1EC & 2650 & 465 & 9160 & 444 & 126 & 3280 & 77.0 & 135 & 69 & 335 \\
\hline NP2EC & 1570 & 351 & 6050 & 394 & 183 & 4270 & 70.0 & 53 & 23 & 168 \\
\hline NP3,4EC & 252 & 91 & 914 & 227 & 120 & 2680 & $-5.8^{\mathrm{a}}$ & 36 & 24 & 101 \\
\hline NP & 473 & 70 & 1240 & 123 & $<29$ & 281 & 76.2 & 64 & $<29$ & 195 \\
\hline $\mathrm{OP}$ & 19 & $<1.2$ & 3860 & 1.3 & $<1.2$ & 8.8 & 89.7 & 2.4 & $<1.2$ & 6.9 \\
\hline $\mathrm{BPA}$ & 414 & 226 & 1640 & 24 & 1.3 & 707 & 74.5 & 9.4 & 2.0 & 46 \\
\hline $\mathrm{PhP}$ & 254 & 98 & 640 & 15 & $<2.1$ & 171 & 92.7 & 6.9 & $<2.1$ & 16 \\
\hline methylparaben & 724 & 65 & 9880 & 11 & 4.6 & 423 & 96 & 5.0 & 3.1 & 17 \\
\hline ethylparaben & 129 & 2.2 & 719 & 0.2 & $<0.3$ & 17 & 98.5 & 0.1 & $<0.3$ & 1.6 \\
\hline propylparaben & 430 & 43 & 1540 & 1.3 & $<0.5$ & 28 & 99.5 & 0.6 & $<0.5$ & 5.8 \\
\hline butylparaben & 211 & 9.7 & 864 & 0.3 & $<0.2$ & 12 & 99.5 & 0.3 & $<0.2$ & 2.8 \\
\hline benzylparaben & 0.2 & $<0.2$ & 4.1 & 0.1 & 0.2 & 16 & $-\mathrm{b}$ & 0.0 & $<0.2$ & 4.4 \\
\hline
\end{tabular}

${ }^{\mathrm{a}}$ For NP3,4EC, an average formation was observed.

${ }^{\mathrm{b}}$ As many samples showed concentrations below limit of detection, a removal efficiency could not be determined.

The current concentrations of NP and BPA in the Glatt are similar to those found in 2004 (Voutsa et al. 2006). High concentrations above $1 \mu \mathrm{gl}^{-1}$ were found for parabens in WWTP influents, whereas their concentrations in river water were in the low nanogram per litre range. The relative concentrations of the five measured parabens reflect their consumption pattern, with methyl- and propylparaben being most abundant.

Based on WWTP effluent and influent concentrations, the efficiencies of EDC removal from the dissolved phase were calculated (table 2). For $\mathrm{PhP}$ and parabens, high removal percentages (averages of $93 \%$ and $98 \%$, respectively) were observed at all WWTPs. Median removal percentages for NP $n \mathrm{EO}$ (greater than $97 \%$ ) were high in all WWTPs, but NP $n$ EO metabolites were not always removed with high efficiency, and at two WWTPs the authors even observed an increase in concentrations of $\mathrm{NP} n \mathrm{EC}$ and $\mathrm{NP}$, metabolites derived from $\mathrm{NP} n \mathrm{EO}$.

Water flows in the study area varied considerably during the sampling period. Two large rain events caused a strong increase in both wastewater and river flows during days 2, 3, 10 and 11. During these high-flow days, the wastewater flow exceeded the WWTP capacities and all WWTPs had to discharge some of the raw wastewater influx directly, without treatment into the Glatt. For most compounds, mass flows in WWTP effluents and in the river became greater with increasing water flows, indicating that pollutants were not diluted in proportion to the increase in flow. In an attempt to achieve mass balances for EDCs in the Glatt River, the total discharge of all known EDC sources (Greifensee outlet and 
WWTP effluents) and the mass flow actually measured at the end of the river were compared. Throughout the low water flow period, mass flows predicted on the basis of the known inputs were similar to the actual mass flows at the end of the river for most analytes. This indicates that during low-flow days, all sources were accounted for, and no significant in-stream removal occurred in the Glatt River. In the periods with high water flows, however, mass flows of $\mathrm{NP} n \mathrm{EC}$ in the river were much higher than could be explained by the initially defined sources. Clearly, on those days, not all $\mathrm{NP} n \mathrm{EC}$ sources were accounted for. It is likely that at least part of the additional $\mathrm{NP} n \mathrm{EC}$ mass during high-flow days originated from the untreated wastewater discharged into the Glatt on these days. With these additional sources included, the predicted mass flows for $\mathrm{NP} n \mathrm{EC}$, $\mathrm{BPA}$ and $\mathrm{PhP}$ were rather similar to the actual ones. Considering discharge of untreated wastewater for $\mathrm{OP}, \mathrm{NP} n \mathrm{EO}$ and methylparaben, however, led to an overprediction of the riverine mass flows, which may mean that these substances were partly degraded in overflow basins. It is even possible that in-stream removal is more efficient during days on which highly biologically active wastewater influent is discharged. Yet during dry periods, only BPA showed a significant in-stream removal, as indicated by comparison of actual and predicted riverine mass flows.

As a conclusion, rain events and corresponding discharges of untreated wastewater appear to be of key importance when considering mass flows of contaminants in the aquatic environment. The study of Jonkers et al. (2009) also conclusively demonstrates that actual chemical monitoring of the water is necessary, as current hydrological fate models based on general consumption data of chemicals do not give any information with regard to the situation during the frequently occurring rain events.

\section{Laboratory studies on biotransformation and effects}

Primary biodegradation of $\mathrm{NP} n \mathrm{EO}$ in WWTPs is quite efficient. However, overall biodegradation seems to be complicated by several bottlenecks that enhance the formation of metabolites, such as NP2EO, NP1EO, NP, NP1EC and NP2EC, and by unspecific oxidation reactions yielding metabolites with oxidized alkyl and ethoxy side chains (CAP $n \mathrm{EC}$ ) (Di Corcia et al. 1998, 2000). These metabolites are not as easily transformed as the parent compounds and transiently accumulate so that they can be found in sewage treatment effluents (Brunner et al. 1988; Ahel et al. 1994a; Field \& Reed 1996; Di Corcia et al. 2000), sewage sludges, rivers (Giger et al. 1984; Ahel et al. 1994b, 2000a,b; Field \& Reed 1996; Jonkers et al. 2001), estuaries (Dachs et al. 1999; Potter et al. 1999; Ferguson et al. 2001; Jonkers et al. 2003), coastal waters (Kvestak et al. 1994) and sediments (Ferguson \& Brownawell 2003; Ferguson et al. 2003).

Transformation of NP $n \mathrm{EO}$ to NP2EO and NP1EO metabolites is well established and bacteria able to grow on $\mathrm{NP} n \mathrm{EO}$ as sole carbon source have been isolated (Maki et al. 1994; John \& White 1998). Such bacteria degrade $\mathrm{NP} n \mathrm{EO}$ by stepwise exo-scission of single glycol units with the accumulation of NP2EO and NP1EO as major end products. The proposed mechanism involves an oxygen-independent hydroxyl shift from the terminal to the penultimate carbon of the terminal ethoxylate unit of $\mathrm{NP} n \mathrm{EO}$ and a 
dissociation of the resulting hemiacetal to release acetaldehyde and the next-lower homologue. This $\mathrm{NP}(n-1) \mathrm{EO}$ metabolite then undergoes further cycles of the same reaction until the ethoxy chain is reduced to two or one ethoxy units (John \& White 1998).

Until recently, transformation reactions of $\mathrm{NP} n \mathrm{EO}$ and its metabolites other than the ones mentioned above were not very well understood in terms of mechanisms and micro-organisms involved. The reaction schemes were mainly based on measuring concentrations of the various metabolites in environmental compartments and microcosm experiments. Such data usually do not allow deciding whether the detected metabolites arise as a consequence of a steadystate situation with relatively high turnover or are slowly accumulating dead end products formed by non-specific side reactions. For selected sewage treatment plants in Switzerland, it has been estimated that - on a molar basis - about 60 per cent of the $\mathrm{NP} n \mathrm{EO}$ were removed and about 40 per cent were released to ambient receiving waters (Ahel et al. 1994a) in the form of NP, NP $n \mathrm{EC}$, NP1EO, $\mathrm{NP} 2 \mathrm{EO}$ and untransformed $\mathrm{NP} n \mathrm{EO}$. About one-third of the removed $\mathrm{NP} n \mathrm{EO}$ was in the form of NP attached to digested sludge and about two-thirds might have been mineralized.

Here we discuss the most recent research findings that help to better understand the microbial metabolism of $\mathrm{NP} n \mathrm{EO}$ and $\mathrm{NP}$ and to shed better light on the role of NP in further transformation of NP1EC. As technical NP is a complex mixture of more than 100 isomers, which differ in the structure and the position of the alkyl moiety attached to the phenol ring (Ieda et al. 2005), the availability and the use of single NP isomers became of utmost importance for the elucidation of the degradation pathway. Throughout this paper, the various 4-NP isomers are numbered according to the systematic numbering systems proposed by Guenther et al. (2006).

\section{(a) Biotransformation of nonylphenol isomers}

First hints that micro-organisms are able to metabolize alkylphenolic compounds such as NP, OP and octylphenoxyacetic acid under aerobic conditions came from studies in which 2,4,4-trimethyl-2-pentanol was detected as a metabolite when OP (Tanghe et al. 2000) and octylphenoxyacetic acid (Fujita \& Reinhard 1997) were incubated with Sphingomonas TTNP3 and groundwater enrichment cultures, respectively. Later, it could be shown that several Sphingomonas strains were able to use NP as sole carbon and energy source (Tanghe et al. 1999; Fujii et al. 2001; Gabriel et al. 2005a), and incubation experiments with these strains and individual NP isomers laid ground for the elucidation of the mechanism of the degradation pathway of NP.

Degradation experiments with defined mixtures of NP isomers indicated that Sphingobium xenophagum strain Bayram differentially transformed these isomers. The degradation rate showed a positive correlation with the branching degree of the alkyl substituent - the more highly branched, the faster the degradation (Gabriel et al. 2005a). These findings strongly contrasted with what had been the prevailing view on the degradation of technical NP mixtures (Tanghe et al. 1999; Topp \& Starratt 2000; Corvini et al. 2004b) and emphasized the importance of considering isomeric effects. 
(a)<smiles>CCCCCCC(C)(O)[N+](=O)[O-]</smiles>

(b)
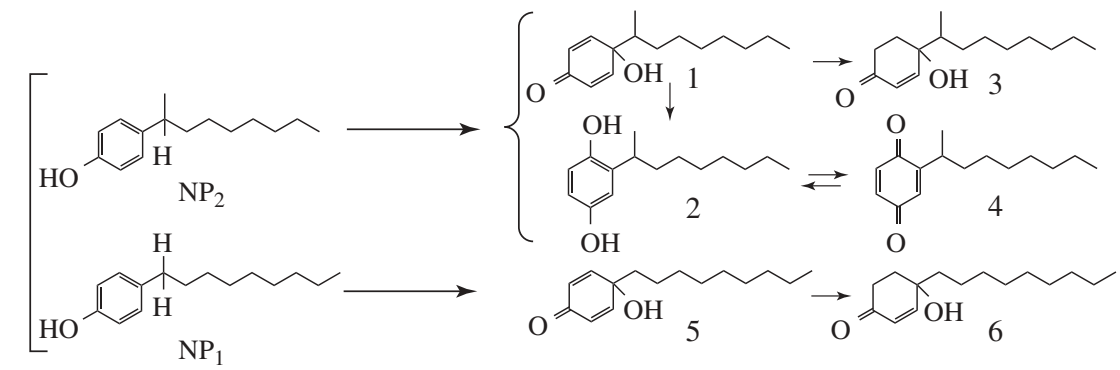

Figure 2. Co-metabolic transformation of $\mathrm{NP}_{1}$ and $\mathrm{NP}_{2}$ and formation of metabolites by strain Bayram in the presence of NP isomers that serve as growth substrates. $(a)$ NP isomers that serve as substrates. (b) Formation of metabolites from NP isomers that do not serve as growth substrates and are only co-metabolically transformed. For details, see Gabriel et al. (2005b, $2007 a)$ and Kohler (2008). Adapted from CHIMIA. Copyright (C) 2008 (Swiss Chemical Society).

Further incubation experiments with a mixture of five isomers led to the detection and identification of nonylalcohols that originated from the isomers with $\alpha$-quaternary carbon atom at the benzylic position (figure 2). However, no traces of potential nonanol metabolites derived from NP isomers with hydrogen atoms at the benzylic position were detected in these experiments, although the corresponding NP isomers were partly degraded. This was an indication that NP isomers with hydrogen atoms at the benzylic position were metabolized differently from the more highly branched isomers. It was proposed (Gabriel et al. 2005a,b; Kohler et al. 2008) that although such isomers do engage in the main degradation pathway, they are only incompletely degraded, because they are unable to undergo the reaction in which the alkyl group is detached from the aromatic part. These data further indicated that the ring moiety had to be cleaved from the alkyl substituent to be used and that the alkyl moieties of the alkylphenol isomers that serve as growth substrates are transformed to alkyl alcohols with retention of the structures of the original alkyl side chains. Conventional pathways of alkylphenol metabolism could not explain the formation of such metabolites.

Growth experiments with strain Bayram and several pure $\alpha$-quaternary 4-NP isomers that could serve as growth substrates $\left(4-\mathrm{NP}_{93}, 4-\mathrm{NP}_{112}\right.$ and $\left.4-\mathrm{NP}_{9}\right)$ did not reveal any metabolites except the $\mathrm{C}_{9}$ alcohols derived from the nonyl side chains (figure $2 a$ ). However, experiments in which non-growth isomers, such as $4-\mathrm{NP}_{2}$ and $4-\mathrm{NP}_{1}$, were co-metabolically transformed in the presence of the growth substrate $4-\mathrm{NP}_{112}$ resulted in the detection of metabolites that could be isolated in milligram quantities (figure $2 b$ ). Their chemical structures were elucidated by NMR spectroscopy and mass spectrometry (Gabriel et al. 2005b). 


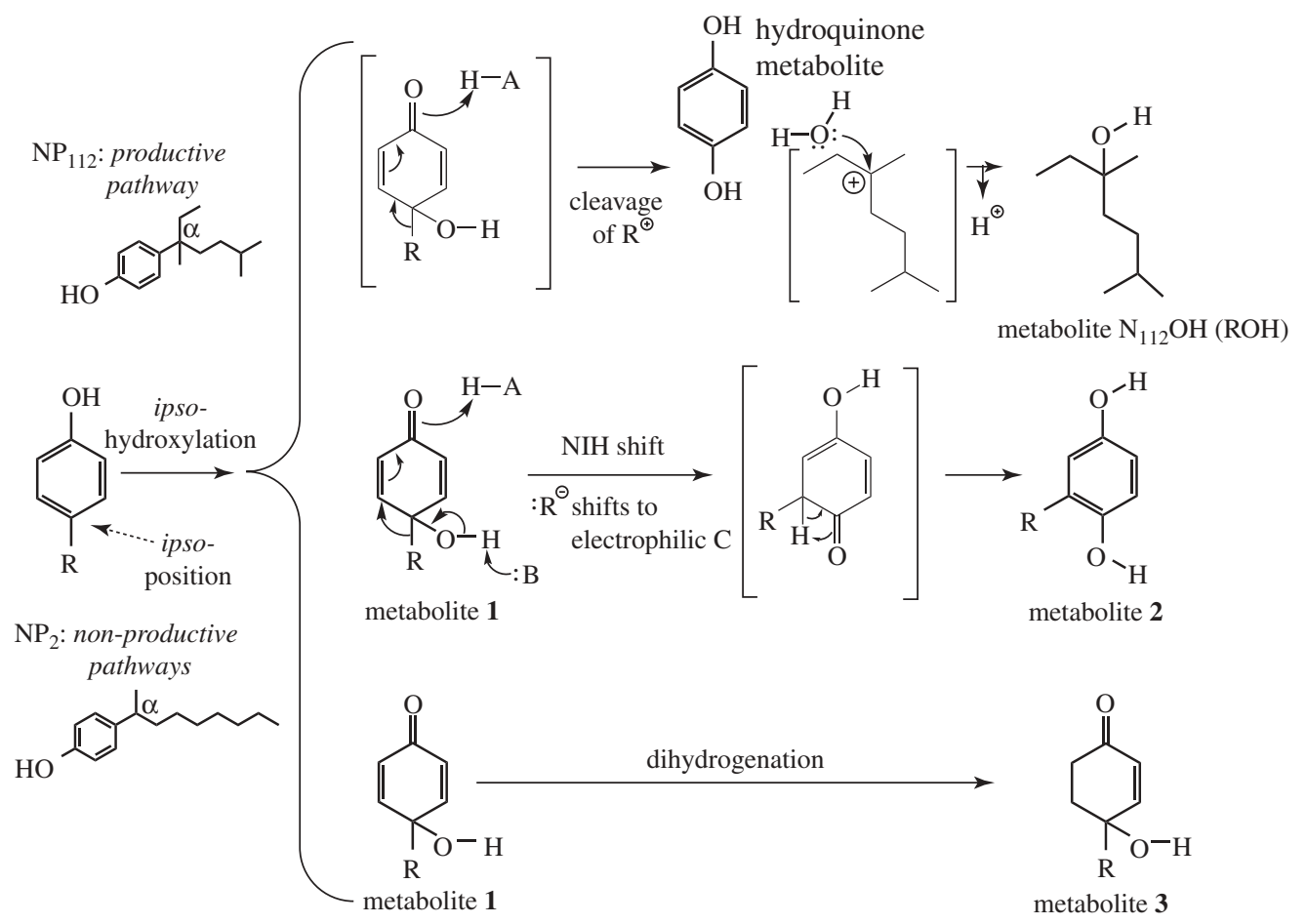

Figure 3. Pathways proposed for the degradation of NP isomers in S. xenophagum Bayram. NPs are transformed by an initial ipso-hydroxylation to 4-alkyl-4-hydroxycyclohexadienone intermediates (e.g. metabolite 1). As an example for a productive pathway (large arrow) NP isomer $\mathrm{NP}_{112}$ and as an example for a non-productive pathway isomer $\mathrm{NP}_{2}$ are shown. $\alpha$-Quaternary intermediates dissociate by releasing the alkyl moiety as a cation, which is stabilized by $\alpha$-alkyl branching. The formed hydroquinone is then further metabolized. Degradation experiments with ${ }^{18} \mathrm{O}$-labelled oxygen and water clearly showed that the detached cation preferentially reacts with the nucleophilic oxygen atom of a water molecule forming the corresponding nonanol (e.g. $\mathrm{N}_{112} \mathrm{OH}$ ), which most likely cannot be further metabolized. 4-Alkyl-4-hydroxycyclohexadienone intermediates with hydrogen at the $\alpha$-position are not able to dissociate at all or they undergo an NIH shift yielding metabolites that cannot be further degraded. A-H and B denote a proton donor and acceptor, respectively. For details, see Kohler (2008). Adapted from CHIMIA. Copyright (C) 2008 (Swiss Chemical Society).

Figure 2 shows these metabolites, and figure 3 shows an NP degradation scheme that is based on the results of these growth experiments. The structures of metabolites $\mathbf{1}$ and $\mathbf{5}$ (figures 2 and 3 ), both with an additional hydroxy substituent at the 4-position of the ring, were strong indicators that the initial reaction was a hydroxylation at the anchor carbon atom of the alkyl substituent-an ipsoattack-yielding 4-alkyl-4-hydroxycyclohexadienones. By analogy, the authors concluded that the growth substrate isomers also underwent an initial ipsohydroxylation. However, intermediates derived from growth substrate isomers did not accumulate, as they spontaneously broke down to the corresponding alkyl cation and hydroquinone (figure 3; Gabriel et al. 2005b, 2007 a).

Experiments with ${ }^{18}$ O-labelled dioxygen and ${ }^{18} \mathrm{O}$-labelled water clearly indicated that the ipso-hydroxy group was derived from molecular dioxygen and the resulting nonanol metabolite contained an oxygen atom from 
water (Gabriel et al. 2007a). These results clearly proved that the initial ipso-hydroxylation reaction in the degradation pathway was catalysed by a monooxygenase and they led to the conclusion that the alkyl cation that was released from the substituted cyclohexadienone intermediate preferentially reacted with water (figure 3, productive pathway) to form the corresponding alcohol. In Sphingomonas sp. TTNP3, nonanols are formed from NP by a similar mechanism (Corvini et al. 2006; Kolvenbach et al. 2007). The breakdown of the 4-alkyl-4-hydroxycyclohexadienone intermediate represents an $\mathrm{S}_{\mathrm{N}} 1$ reaction, whereby the carbocation reacts with the solvent and the dissociation energy is provided by rearomatization of the leaving carbon ring. In contrast to the substituted cyclohexadienones derived from $\alpha$-quaternary NPs, metabolites 1 and $\mathbf{5}$ did not undergo detachment of the alkyl moiety because the corresponding $\alpha$-carbocations were not sufficiently stabilized by alkyl substituents in $\alpha$-position, but they might serve as substrates for side reactions (figures 2 and 3 ).

The formation of metabolite 2 (figures 2 and 3), a 2-alkylhydroquinone, involves a $(1,2-\mathrm{C}, \mathrm{C})$-shift of the alkyl substituent, a reaction well known as NIH shift (Gabriel et al. 2005b), and most likely represents a non-productive side reaction that only becomes relevant when other reactions are unfavourable as is the case for 4-NP isomers with hydrogen atoms at the benzylic $\alpha$-carbon. Small amounts of NIH-shift products have also been detected in cell extracts of other NP degrading strains (Corvini et al. 2004a).

Laboratory experiments revealed that $S$. xenophagum strain Bayram significantly changed the isomer distribution pattern of technical NP when growing with this substrate as the sole carbon and energy source (Gabriel et al. 2008). Figure 4 depicts the outcome of such an 'ageing' experiment, in which about 86 per cent of 4-NP was consumed during 9 days of incubation. A strong correlation between transformation of individual isomers and their $\alpha$-substitution pattern was observed. As a rule, isomers with less bulkiness at the $\alpha$-carbon and those with an optimally sized main alkyl chain (four to six carbon atoms) were degraded most efficiently. The authors concluded that differential microbial metabolism of technical NP mixtures, as observed in the laboratory experiments, will ultimately lead to changes in the relative composition of partially degraded material in the environment. They argued that environmental NP isomer patterns as observed in Tokyo Bay (Horii et al. 2004) and in composted biosolids (Das \& Xia 2008) may be well explained by the in situ activity of bacterial strains that metabolize NPs by ipso-substitution, as strain Bayram does. In the future, detailed analysis and comparison of NP isomer patterns in different environmental compartments will certainly be a valuable means of helping to reveal the dominating transformation processes in such compartments.

\section{(b) Biotransformation of nonylphenoxyacetic acid}

Although NP1EC and NP2EC are the dominating NP $n$ EO metabolites in secondary effluents of sewage treatment plants (Ahel et al. 1987, 1994a), not much is known about further metabolism of these compounds. However, two recent studies (Wettstein 2004; Montgomery-Brown et al. 2008) gave indications that NP1EC is metabolized via NP. In one study, the authors performed aerobic and microaerobic microcosm experiments, in which they incubated NP1EC with organic carbon-poor soils from Arizona as well as with organic carbon-rich 


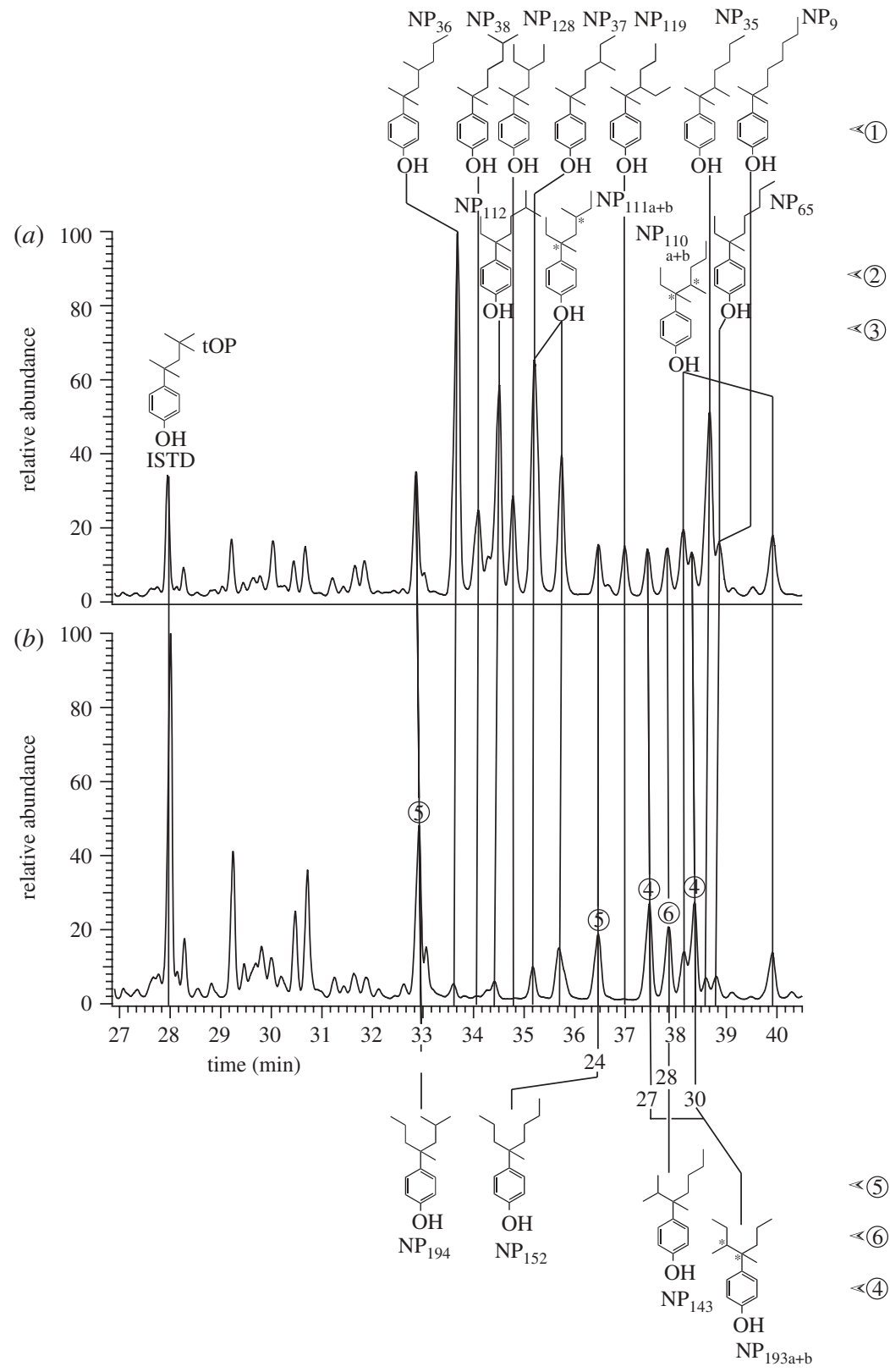

Figure 4. Ageing of technical NP as a result of degradation by S. xenophagum Bayram in minimal medium. GC/MS chromatograms (total ion current) of the culture extracts correspond to (a) the start of the experiment and $(b)$ day 9 of the incubation. Note that differential degradation leads to a significant change in the isomer distribution of the NP mixture. The isomer pattern in the noninoculated control was identical to that of non-degraded technical NP $(a)$. Peaks of recalcitrant isomers (groups 4, 6, and 5) are highlighted (encircled numbers). The great majority of peaks eluting before peak 1 most likely correspond to ortho-isomers. Signals were numbered according to their retention time. The vertical position of a mass spectrometric group indicates the recalcitrance of its members to biodegradation by strain Bayram (group numbers - encircled numbers at the far right-are listed according to increased recalcitrance). Adapted from Environmental Science and Technology. Copyright (C) 2008 (American Chemical Society).

Phil. Trans. R. Soc. A (2009) 


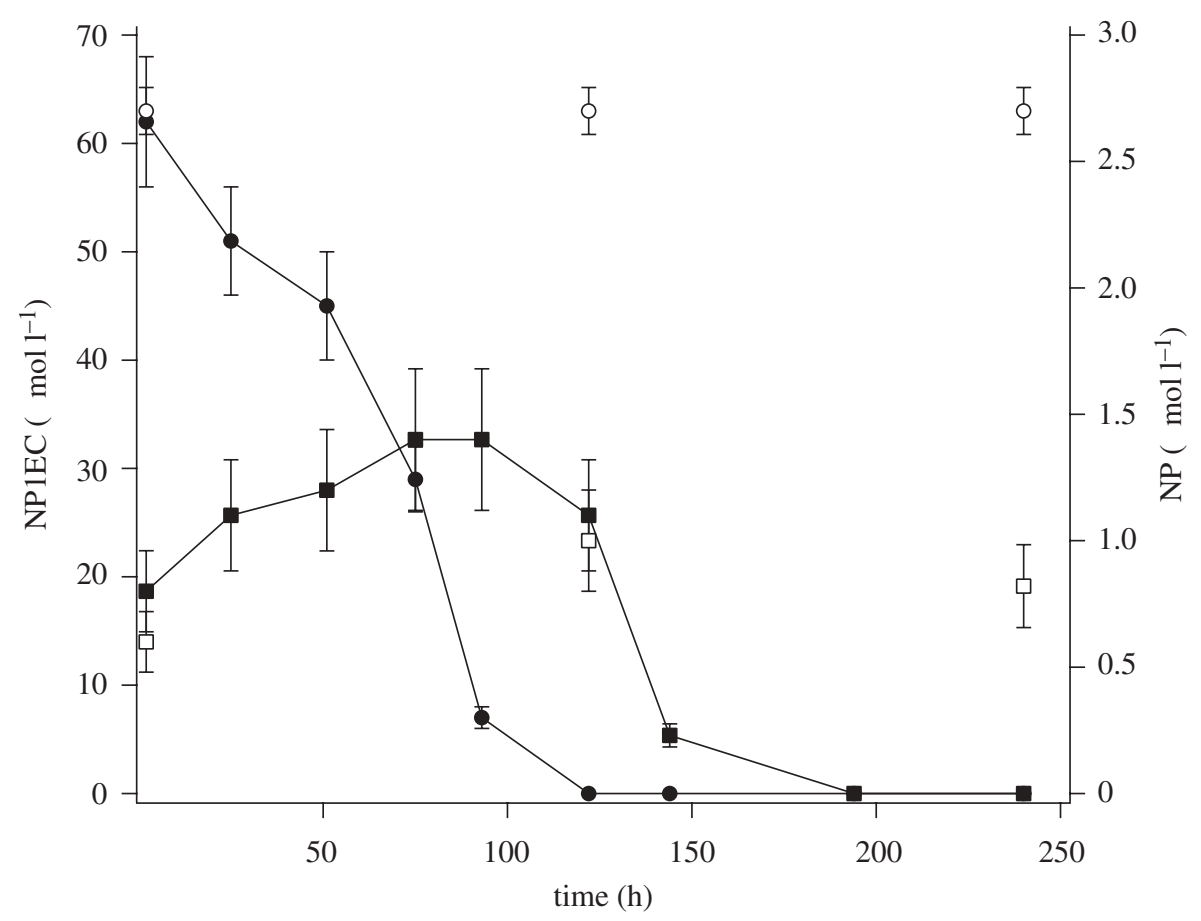

Figure 5. Aerobic degradation of NP1EC incubated with activated sludge from a sewage treatment plant. Besides the progress curves for NP1EC (filled circles) and NP (filled squares), values for the sterile controls for NP1EC (open circles) and NP (open squares) are shown. For details, see Wettstein (2004).

sediments from California (Montgomery-Brown et al. 2008). The results suggested that the oxygen tension determined the dominant biodegradation pathway. Under fully aerobic conditions (Arizona soils), ether cleavage with formation and subsequent degradation of NP was favoured, while under microaerobic conditions (California sediments) alkyl chain oxidation with formation of $\mathrm{CAP} n \mathrm{EC}$ was favoured. The authors clearly showed that in the microcosms with Arizona soils (high oxygen tension) para-NP1EC was transformed to paraNP, which was then quickly turned over to nonyl alcohols by ipso-hydroxylation (Montgomery-Brown et al. 2008).

In the second study, degradation experiments with activated sludge from a municipal WWTP in Switzerland were performed under aerobic conditions (Wettstein 2004). Figure 5 shows that in such incubations NP transiently increased during degradation of NP1EC. At the end of the experiment, both NP1EC and NP were completely metabolized. The fact that the transient accumulation of NP was not very pronounced indicates that under such conditions the rate limiting process most likely was the transformation of NP1EC to NP. This also might explain why the formation of NP from NP $n$ EC under aerobic conditions has not been observed previously in studies on the environmental fate of $\mathrm{NP} n \mathrm{EC}$ (Fujita \& Reinhard 1997; Potter et al. 1999; Wild \& Reinhard 1999). 


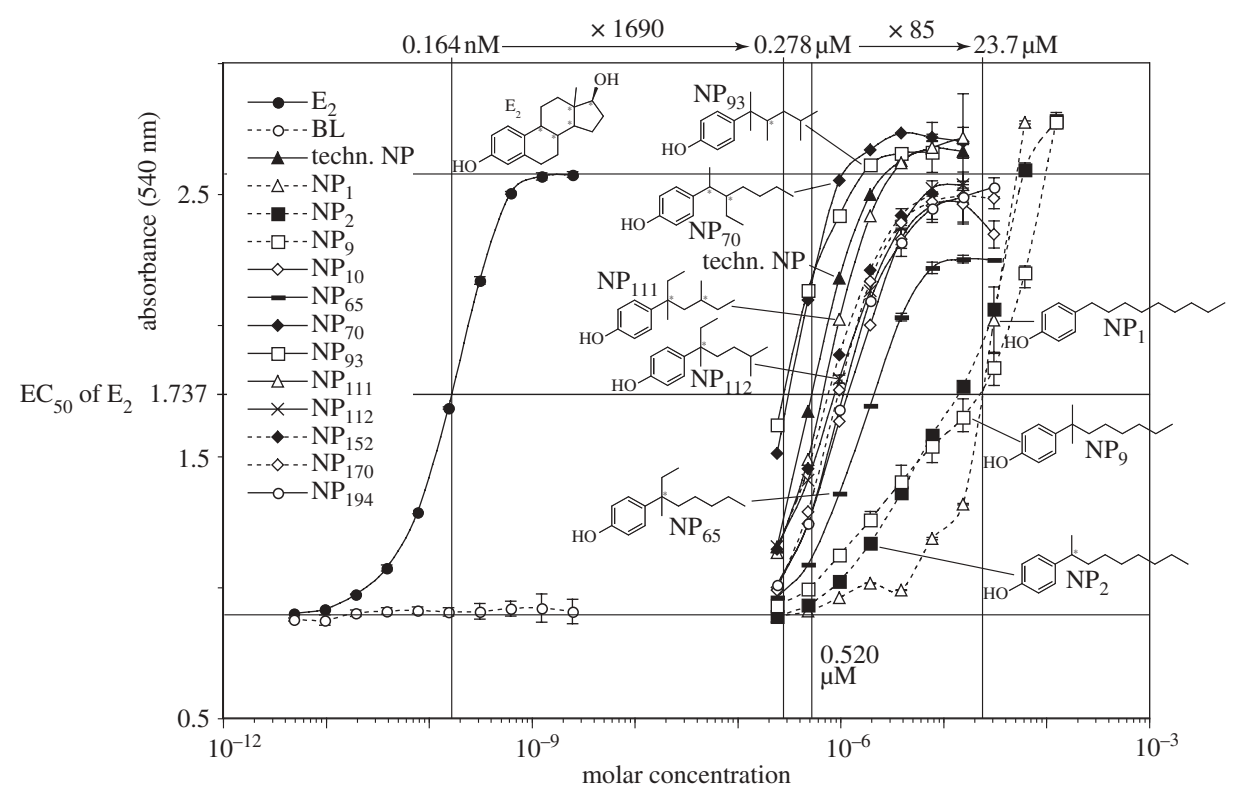

Figure 6. Endocrine activity (YES assay) of a range of NP isomers. The graph depicts the logarithmic concentration of $17 \beta$-oestradiol $\left(\mathrm{E}_{2}\right)$ serially diluted from $2.5 \mathrm{nM}$ to $4.9 \mathrm{pM}$ and of NP isomers diluted from 0.13 to $0.24 \mu \mathrm{M}$, plotted against the absorbance of the medium after a 3 -day incubation at $32^{\circ} \mathrm{C}$. The blank (BL) shows the response of the assay in the absence of test compound. Values represent mean \pm standard deviation from duplicate wells. Structures of selected test compounds are shown. The vertical lines depict the concentrations used to determine the potencies of $\mathrm{NP}_{93}, \mathrm{NP}_{1}$ (the most and least potent isomers of our test series, respectively) and $17 \beta$-oestradiol, relative to that of technical NP. For details, see Gabriel et al. (2008). Adapted from Environmental Science and Technology. Copyright (C) 2008 (American Chemical Society).

\section{(c) Oestrogenic activity of nonylphenol isomers}

Three recent studies clearly demonstrate that NP isomers differ in oestrogenic activity (Preuss et al. 2006; Shioji et al. 2006; Gabriel et al. 2008). Figure 6 shows the response of the yeast oestrogen screen (YES) to various concentrations of a range of NP isomers (Gabriel et al. 2008). The NP isomers generally produced full dose response curves over a range of two orders of magnitude, with the most potent isomer $\left(\mathrm{NP}_{93}\right)$ being only about 1700 times less potent than $17 \beta$ oestradiol, and nearly twice as potent as the technical mixture of isomers. Despite the difference in cell reporter systems used and except for one NP isomer, the oestrogenicity rankings of the three studies were in excellent agreement. The results of the three studies also well support the hypothesis of Shioji et al. (2006) that an optimal length of the main alkyl chain (four to six carbon atoms) together with bulkiness around the $\beta$ - and $\gamma$-position is necessary for high oestrogenicity, whereas the presence of $\alpha$-substituents is less important.

Differential degradation of NP isomers together with the fact that NP isomers have different oestrogenic activities has significant implications for future risk assessments. Analysis of the degradation experiment with technical NP indicated that isomers with sterically hindering $\alpha$-substituents tend 
to be recalcitrant. This holds well for, for example, $\mathrm{NP}_{193 a}$ and $\mathrm{NP}_{193 b}$, which have bulky $\alpha-\mathrm{CH}_{3}, \alpha-\mathrm{CH}\left(\mathrm{CH}_{3}\right) \mathrm{C}_{2} \mathrm{H}_{5}$ substitutions and are the most recalcitrant among the main isomers in technical NP (Gabriel et al. 2008). However, they are also characterized by $\beta$-substitution and by a main alkyl chain of four carbon atoms, which implies high oestrogenic activity. It is clear that if recalcitrant components of technical NP prove to be highly oestrogenic, then there is a substantial risk that microbial degradation by ipso-substitution will increase the specific oestrogenicity of the remaining material. Further research on varying isomer composition and oestrogenicity of NP mixtures during microbial degradation will be needed to establish whether certain highly oestrogenic isomers are recalcitrant and whether microbial transformation indeed increases the specific oestrogenicity of technical NP in the environment.

\section{(d) New views on microbial transformations of nonylphenolic compounds}

Figure 7 shows a schematic overview of biotransformation reactions that have been described to date (see also Montgomery-Brown \& Reinhard 2003; Kohler et al. 2008, and references therein). As pointed out in this paper, it is now well established that certain bacteria are able to degrade NP by ipso-substitution (figure 7 , reaction 1). These bacteria are able to grow at the expense of the aromatic part of the molecule and leave behind the alkyl side chain as the corresponding alkyl alcohol, whose ultimate fate still remains unknown. We also presented new information on the microbial transformation of NP1EC, as there are now strong indications that NP1EC is metabolized via NP (figure 7, reaction 2). However, we now also realize that certain transformation reactions in the reaction network shown in figure 7 (especially reactions 1 and 3) are isomer specific. This means that the rate or the extent of the transformation or both are dependent on the isomeric structure of the alkyl side chain of a specific NP isomer. To be transformed by ipso-substitution NP isomers require $\alpha$-quaternary carbon atoms as structural components; however, the bulkiness of these $\alpha$-substitutions is another critical factor that determines transformability by ipso-substitution. The degradation ranking established for differential degradation of technical NP by strain Bayram clearly indicated that degradation was more effective when the $\alpha$-position was less bulky. The length of the main alkyl chain also seems to play an important steric role, as isomers with little bulkiness at the $\alpha$-position but lengthy alkyl chains were rather slowly transformed (Gabriel et al. 2008). From these findings, we can safely conclude that differential microbial metabolism of technical NP mixtures by ipso-substitution will ultimately lead to changes in the relative composition of the remaining material. We therefore suggest that NP residues in different environmental matrices will be characterized by distinct isomeric fingerprints that depend on the grade of degradation and on the dominating degradation process.

Furthermore, isomer selectivity is also evident for reaction 3, the formation of $\mathrm{CAP} n \mathrm{EC}$ from $\mathrm{NP} n \mathrm{EC}$ (Montgomery-Brown et al. 2008). The authors observed accumulation of only certain $\mathrm{CA}_{6} \mathrm{PEC}$ isomers in their microcosm experiments, which is a strong indication that $\mathrm{CAP} n \mathrm{EC}$ formation or removal processes are isomer selective. As $\omega$-oxidation with a subsequent $\beta$-oxidation step has been suggested to be the dominant process for the formation of $\mathrm{CA}_{6} \mathrm{PEC}$, it 

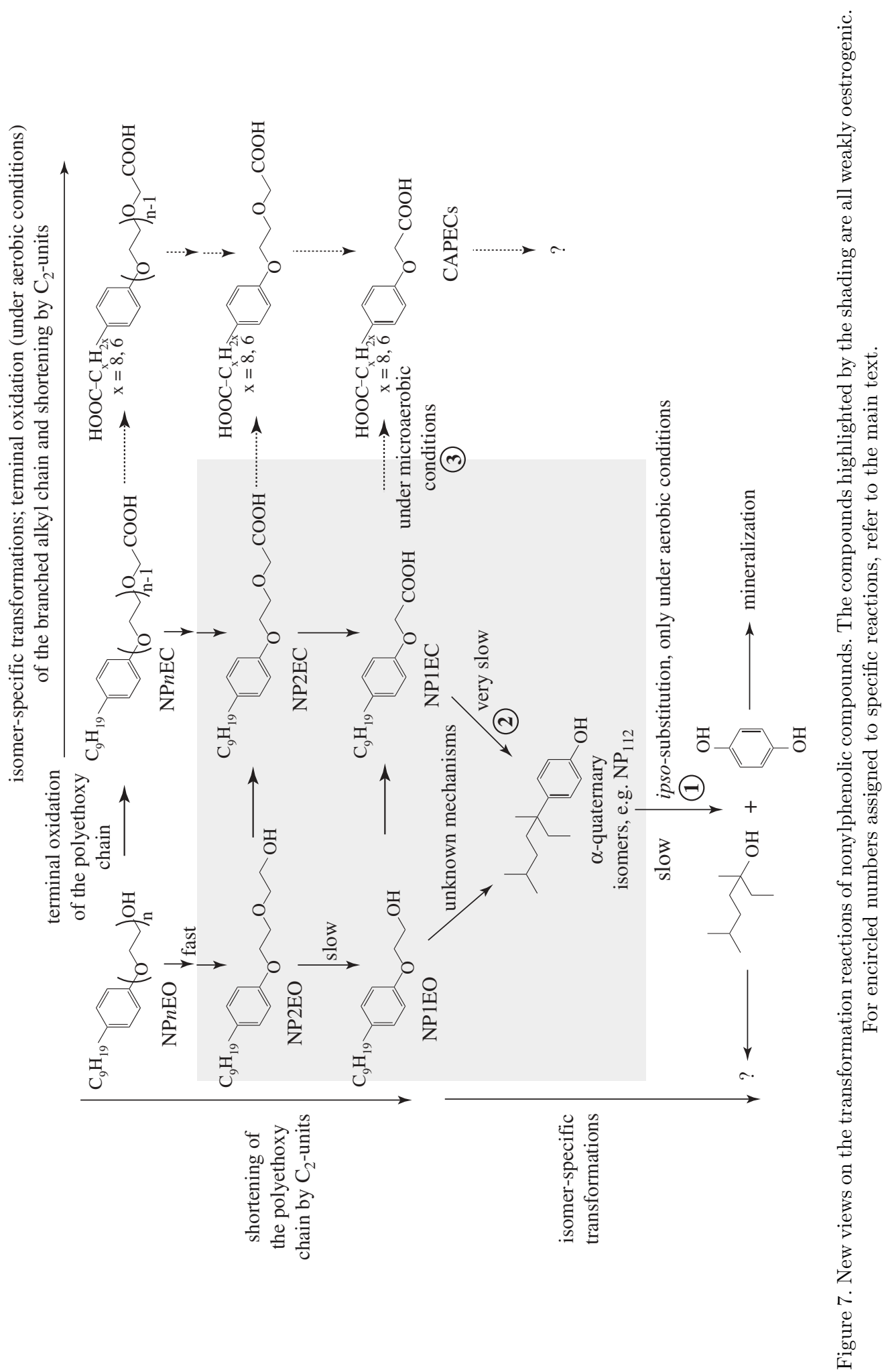
is reasonable to assume with regard to technical NP that only isomers with a main alkyl chain length of more than three carbon atoms and without terminal or sub-terminal alkyl chain branching will be able to undergo chain shortening by $\beta$-oxidation; e.g. $\mathrm{NP}_{9}$ and $\mathrm{NP}_{35}$ would be expected to be transformed into $\mathrm{CA}_{6} \mathrm{PEC}$ under suitable conditions, whereas $\mathrm{NP}_{38}, \mathrm{NP}_{37}$ and $\mathrm{NP}_{111}$ would not.

Figure 7 also conveys the notion that microbial transformation of $\mathrm{NP} n \mathrm{EO}$ comprises a network of transformation reactions, each being selective to a certain degree and dependent on certain conditions. For a specific nonylphenolic compound, the dominant reaction pathway and therefore the ultimate fate of the compound will depend on the compound's isomeric structure and other chemical properties as well as on the prevailing reaction conditions. Especially, oxygen availability is a significant environmental reaction parameter. Under strict anaerobic conditions, NP turned out to be the end product of $\mathrm{NP} n \mathrm{EO}$ transformation (Ahel et al. 1994a,b; Montgomery-Brown \& Reinhard 2003; Wettstein 2004). Under aerobic conditions further transformation of certain NP isomers by ipso-substitution (Gabriel et al. 2007a,b, 2008; Kohler et al. 2008) and the formation of $\mathrm{CAP} n \mathrm{EC}$ from $\mathrm{NP} n \mathrm{EC}$ is possible. Moreover, oxygen tension also seems to be an important factor in determining the reaction pathway of $\mathrm{NP} n \mathrm{EC}$. Under low oxygen tension, formation of $\mathrm{CAP} n \mathrm{EC}$ is significant, whereas under high oxygen tension further metabolism via NP and subsequent ipso-substitution is favoured (Montgomery-Brown et al. 2008).

\section{Conclusions and outlook}

Our several decades long involvement in work on the environmental fate and effects of phenolic and in particular alkylphenolic chemicals has shown us many times the pivotal importance of multi-disciplinary cooperation of analytical and environmental chemists, microbiologists, environmental engineers and ecotoxicologists. Only through such close cooperation could the presented insights be achieved. Publications of projects deficient of such an interdisciplinary approach clearly lack optimum performance.

Steadily advancing analytical chemical methodology will continue to increase the knowledge obtainable from full-scale treatment plants, ambient waters and laboratory investigations. Important developments are on-line enrichment and large-volume injections into ultra-efficient LC systems coupled to multistage and high-resolution mass spectrometry. It can be expected that future routine methods will operate without time and labour consuming offline enrichment of trace constituents in aqueous samples. But also multidimensional chromatographic systems such as comprehensive two-dimensional gas chromatography/time-of-flight mass spectrometry (GCGC/TOFMS) have started contributing to the efficient analyses of complex isomeric mixtures such as technical NP (Eganhouse et al. submitted).

In order to get reliably interpretable results from full-scale studies in wastewater treatment and particularly in ambient water systems, there is a clear need for sophisticated and extensive sampling concepts. Otherwise, the highly complex input situations and the impact of hydrological dynamics are not sufficiently considered. We very much doubt whether small numbers of grab samples from larger rivers or very different river types distributed all over 
Europe and with no control on the hydrological situations can provide reliable databases. Our data from the Glatt River in Switzerland clearly show that such a relatively small river catchment system is already highly dynamic under different weather conditions.

All the new findings of the laboratory studies described in this paper help to better understand the microbial metabolism and the environmental fate of nonylphenolic compounds. But they also have led us to realize that a network of various reactions leads to a plethora of possible metabolites depending on isomeric structures and environmental conditions. Because of bottlenecks in reaction pathways, such metabolites might be present at significant steady-state concentrations in certain environments even when the prevailing reaction pathways ultimately lead to mineralization.

Much of the research described in this article was financially supported by the Swiss National Science Foundation within the framework of the National Research Programme NRP50 'Endocrine Disruptors: Relevance to Humans, Animals and Ecosystems'. We very much acknowledge the comments made by Marijan Ahel and Alfredo Alder on a draft of this article.

\section{References}

Ahel, M. 1987 Biogeochemical behaviour of alkylphenol polyethoxylates in the aquatic environment. PhD thesis, University of Zagreb.

Ahel, M. \& Giger, W. 1985a Determination of alkylphenols and alkylphenol monoethoxylate and diethoxylate in environmental samples by high-performance liquid chromatography. Anal. Chem. 57, 1577-1583. (doi:10.1021/ac00285a018)

Ahel, M. \& Giger, W. $1985 b$ Determination of nonionic surfactants of the alkylphenol poylethoxylate type by high-performance liquid chromatography. Anal. Chem. 57, 2584-2590. (doi:10.1021/ac00290a035)

Ahel, M., Conrad, T. \& Giger, W. 1987 Persistent organic chemicals in sewage effluents. 3. Determinations of nonylphenoxy carboxylic acids by high-resolution gas-chromatography mass spectrometry and high-performance liquid chromatography. Environ. Sci. Technol. 21, 697-703. (doi:10.1021/es00161a011)

Ahel, M., Giger, W. \& Koch, M. $1994 a$ Behavior of alkylphenol polyethoxylate surfactants in the aquatic environment. 1. Occurrence and transformation in sewage treatment. Water Res. 28, 1131-1142. (doi:10.1016/0043-1354(94)90200-3)

Ahel, M., Giger, W. \& Schaffner, C. $1994 b$ Behavior of alkylphenol polyethoxylate surfactants in the aquatic environment. 2. Occurrence and transformation in rivers. Water Res. 28, 1143-1152. (doi:10.1016/0043-1354(94)90201-1)

Ahel, M., Schaffner, C. \& Giger, W. 1996 Behaviour of alkylphenol polyethoxylate surfactants in the aquatic environment. 3. Occurrence and elimination of their persistent metabolites during infiltration of river water to groundwater. Water Res. 30, 37-46. (doi:10.1016/0043-1354 (95)00123-3)

Ahel, M., Giger, W., Molnar, E. \& Ibric, S. $2000 a$ Determination of nonylphenol polyethoxylates and their lipophilic metabolites in sewage effluents by normal-phase high-performance liquid chromatography and fluorescence detection. Croat. Chem. Acta 73, 209-227.

Ahel, M., Molnar, E., Ibric, S. \& Giger, W. $2000 b$ Estrogenic metabolites of alkylphenol polyethoxylates in secondary sewage effluents and rivers. Water Sci. Technol. 42, 15-22.

Boehme, R. M., Andries, T., Dötz, K. H., Thiele, B. \& Guenther, K. Submitted. Synthesis of defined endocrine-disrupting nonylphenol isomers for biological and environmental studies.

Brunner, P. H., Capri, S., Marcomini, A. \& Giger, W. 1988 Occurrence and behaviour of linear alkylbenzenesulphonates, nonylphenol, nonylphenol mono- and nonylphenol diethoxylates in sewage and sewage sludge treatment. Water Res. 22, 1465-1472. (doi:10.1016/0043-1354 (88)90157-1)

Phil. Trans. R. Soc. A (2009) 
Comber, M. H. I., Williams, T. D. \& Stewart, K. M. 1993 The effects of nonylphenol on Daphnia magna. Water Res. 27, 273-276. (doi:10.1016/0043-1354(93)90086-W)

Corvini, P. F. X., Meesters, R. J. W., Schäffer, A., Schröder, H. F., Vinken, R. \& Hollender, J. 2004a Degradation of a nonylphenol single isomer by Sphingomonas sp. strain TTNP3 leads to a hydroxylation-induced migration product. Appl. Environ. Microbiol. 70, 6897-6900. (doi:10.1128/AEM.70.11.6897-6900.2004)

Corvini, P. F. X., Vinken, R., Hommes, G., Schmidt, B. \& Dohmann, M. $2004 b$ Degradation of the radioactive and non-labelled branched $4\left(3^{\prime}, 5^{\prime}\right.$-dimethyl- $3^{\prime}$-heptyl $)$-phenol nonylphenol isomer by Sphingomonas TTNP3. Biodegradation 15, 9-18. (doi:10.1023/B:BIOD.0000009937. 20251.d2)

Corvini, P. F. X., Hollender, J., Ji, R., Schumacher, S., Prell, J., Hommes, G., Priefer, U., Vinken, R. \& Schäffer, A. 2006 The degradation of $\alpha$-quaternary nonylphenol isomers by Sphingomonas sp. strain TTNP3 involves a type II ipso-substitution mechanism. Appl. Microbiol. Biotechnol. 70, 114-122. (doi:10.1007/s00253-005-0080-0)

Dachs, J., Van Ry, D. A. \& Eisenreich, S. J. 1999 Occurrence of estrogenic nonylphenols in the urban and coastal atmosphere of the lower Hudson river estuary. Environ. Sci. Technol. 33, 2676-2679. (doi:10.1021/es990253w)

Das, K. C. \& Xia, K. 2008 Transformation of 4-nonylphenol isomers during biosolids composting. Chemosphere 70, 761-768. (doi:10.1016/j.chemosphere.2007.07.039)

Di Corcia, A., Costantino, A., Crescenzi, C., Marinoni, E. \& Samperi, R. 1998 Characterization of recalcitrant intermediates from biotransformation of the branched alkyl side chain on nonylphenol ethoxylate surfactants. Environ. Sci. Technol. 32, 2401-2409. (doi:10.1021/ es9801285)

Di Corcia, A., Cavallo, R., Crescenzi, C. \& Nazzari, M. 2000 Occurrence and abundance of dicarboxylated metabolites of nonylphenol polyethoxylate surfactants in treated sewages. Environ. Sci. Technol. 34, 3914-3919. (doi:10.1021/es001208n)

Eganhouse, R. P., Pontolillo, J., Gaines, R. D., Frysinger, G. S., Gabriel, F. L. P., Kohler, H. P. E., Giger, W. \& Barber, L. B. Submitted. Isomer-specific determination of 4-nonylphenols using comprehensive two-dimensional gas chromatography/time-of-flight mass spectrometry.

Ferguson, P. L. \& Brownawell, B. J. 2003 Degradation of nonylphenol ethoxylates in estuarine sediments under aerobic and anaerobic conditions. Environ. Toxicol. Chem. 22, 1189-1199. (doi:10.1897/1551-5028(2003)022<1189:DONEIE $>2.0$. CO;2)

Ferguson, P. L., Iden, C. R. \& Brownawell, B. J. 2001 Distribution and fate of neutral alkylphenol ethoxylate metabolites in a sewage-impacted urban estuary. Environ. Sci. Technol. 35, 2428-2435. (doi:10.1021/es001871b)

Ferguson, P. L., Bopp, R. F., Chillrud, S. N., Aller, R. C. \& Brownawell, B. J. 2003 Biogeochemistry of nonylphenol ethoxylates in urban estuarine sediments. Environ. Sci. Technol. 37, 3499-3506. (doi:10.1021/es026335t)

Field, J. A. \& Reed, R. L. 1996 Nonylphenol polyethoxy carboxylate metabolites of nonionic surfactants in U.S. paper mill effluents, municipal sewage treatment plant effluents, and river waters. Environ. Sci. Technol. 30, 3544-3550. (doi:10.1021/es960191z)

Fujii, K., Urano, N., Ushio, H., Satomi, M. \& Kimura, S. 2001 Sphingomonas cloacae sp. nov., a nonylphenol-degrading bacterium isolated from wastewater of a sewage-treatment plant in Tokyo. Int. J. Syst. Evol. Microbiol. 51, 603-610.

Fujita, Y. \& Reinhard, M. 1997 Identification of metabolites from the biological transformation of the nonionic surfactant residue octylphenoxyacetic acid and its brominated analog. Environ. Sci. Technol. 31, 1518-1524. (doi:10.1021/es9607852)

Gabriel, F. L. P., Giger, W., Guenther, K. \& Kohler, H.-P. E. 2005 a Differential degradation of nonylphenol isomers by Sphingomonas xenophaga Bayram. Appl. Environ. Microbiol. 71, 1123-1129. (doi:10.1128/AEM.71.3.1123-1129.2005)

Gabriel, F. L. P., Heidlberger, A., Rentsch, D., Giger, W., Guenther, K. \& Kohler, H.-P. E. $2005 b$ A novel metabolic pathway for degradation of 4-nonylphenol environmental contaminants by Sphingomonas xenophaga Bayram. ipso-Hydroxylation and intramolecular rearrangement. $J$. Biol. Chem. 280, 15 526-15 533. (doi:10.1074/jbc.M413446200)

Phil. Trans. R. Soc. A (2009) 
Gabriel, F. L. P., Cyris, M., Jonkers, N., Giger, W., Guenther, K. \& Kohler, H.-P. E. $2007 a$ Elucidation of the ipso-substitution mechanism for side-chain cleavage of $\alpha$-quaternary 4 nonylphenols and 4-t-butoxyphenol in Sphingobium xenophagum Bayram. Appl. Environ. Microbiol. 73, 3320-3326. (doi:10.1128/AEM.02994-06)

Gabriel, F. L. P., Cyris, M., Giger, W. \& Kohler, H.-P. E. 2007 b ipso-Substitution: a general biochemical and biodegradation mechanism to cleave $\alpha$-quaternary alkylphenols and bisphenol A. Chem. Biodivers. 4, 2123-2137. (doi:10.1002/cbdv.200790170)

Gabriel, F. L. P., Routledge, E. J., Heidlberger, A., Rentsch, D., Guenther, K., Giger, W., Sumpter, J. P. \& Kohler, H. P. E. 2008 Isomer-specific degradation and endocrine disrupting activity of nonylphenols. Environ. Sci. Technol. 42, 6399-6408. (doi:10.1021/es800577a)

Giger, W. 2009 Hydrophilic and amphiphilic water pollutants: using advanced analytical methods for classic and emerging contaminants. Anal. Bioanal. Chem. 393, 37-44. (doi:10.1007/s00216-008-2481-2)

Giger, W., Stephanou, E. \& Schaffner, C. 1981 Persistent organic chemicals in sewage effluents. 1. Identifications of nonylphenols and nonylphenolethoxylates by glass capillary gas chromatography/mass spectrometry. Chemosphere 10, 1253-1263. (doi:10.1016/0045-6535(81) 90042-4)

Giger, W., Brunner, P. H. \& Schaffner, C. 1984 4-Nonylphenol in sewage sludge: accumulation of toxic metabolites from nonionic surfactants. Science 225, 623-625. (doi:10.1126/ science.6740328)

Gonzalez, S., Petrovic, M. \& Barceló, D. 2007 Advanced liquid chromatography mass spectrometry (LC-MS) methods applied to wastewater removal and the fate of surfactants in the environment. Trends Anal. Chem. 26, 116-124. (doi:10.1016/j.trac.2006.12.003)

Guenther, K., Kleist, E. \& Thiele, B. 2006 Estrogen-active nonylphenols from an isomer-specific viewpoint: a systematic numbering system and future trends. Anal. Bioanal. Chem. 384, 542546. (doi:10.1007/s00216-005-0181-8)

Horii, Y., Katase, T., Kim, Y.-S. \& Yamashita, N. 2004 Determination of individual nonylphenol isomers in water samples by using relative response factor method. Bunseki Kagaku 53, 11391147. (doi:10.2116/bunsekikagaku.53.1139)

Ieda, T., Horii, Y., Petrick, G., Yamashita, N., Ochiai, N. \& Kannan, K. 2005 Analysis of nonylphenol isomers in a technical mixture and in water by comprehensive twodimensional gas chromatography-mass spectrometry. Environ. Sci. Technol. 39, 7202-7207. (doi:10.1021/es050568d)

Jobling, S. \& Sumpter, J. P. 1993 Detergent components in sewage effluent are weakly oestrogenic to fish: an in vitro study using rainbow trout (Oncorhynchus mykiss) hepatocytes. Aquat. Toxicol. 27, 361-372. (doi:10.1016/0166-445X(93)90064-8)

John, D. M. \& White, G. F. 1998 Mechanism for biotransformation of nonylphenol polyethoxylates to xenoestrogens in Pseudomonas putida. J. Bacteriol. 180, 4332-4338.

Jonkers, N., Knepper, T. P. \& De Voogt, P. 2001 Aerobic biodegradation studies of nonylphenol ethoxylates in river water using liquid chromatography-electrospray tandem mass spectrometry. Environ. Sci. Technol. 35, 335-340. (doi:10.1021/es000127o)

Jonkers, N., Laane, R. W. P. M. \& De Voogt, P. 2003 Fate of nonylphenol ethoxylates and their metabolites in two Dutch estuarines: evidence of biodegradation in the field. Environ. Sci. Technol. 37, 321-327. (doi:10.1021/es020121u)

Jonkers, N., Kohler, H.-P. E., Dammshäuser, A. \& Giger, W. 2009 Mass flows of endocrine disruptors in the Glatt River during varying weather conditions. Environ. Pollut. 157, 714-723. (doi:10.1016/j.envpol.2008.11.029)

Kohler, H. P. E., Gabriel, F. L. P. \& Giger, W. 2008 ipso-Substitution - a novel pathway for microbial metabolism of endocrine-disrupting 4-nonylphenols, 4-alkoxyyphenols, and bisphenol A. Chimia 62, 358-363. (doi:10.2533/chimia.2008.358)

Kolvenbach, B., Schlaich, N., Raoui, Z., Prell, J., Zühlke, S., Schäffer, A., Guengerich, F. P. \& Corvini, P. F. X. 2007 Degradation pathway of bisphenol A: does ipso substitution apply to phenols containing a quaternary $\alpha$-carbon structure in the para position? Appl. Environ. Microbiol. 73, 4776-4784. (doi:10.1128/AEM.00329-07) 
Kvestak, R., Terzic, S. \& Ahel, M. 1994 Input and distribution of alkylphenol polyethoxylates in a stratified estuary. Mar. Chem. 46, 89-100. (doi:10.1016/0304-4203(94)90048-5)

Loos, R., Hanke, G., Umlauf, G. \& Eisenreich, S. J. 2007 LC-MS-MS analysis and occurrence of octyl- and nonylphenol, their ethoxylates and their carboxylates in Belgian and Italian textile industry, waste water treatment plant effluents and surface waters. Chemosphere 66, 690-699. (doi:10.1016/j.chemosphere.2006.07.060)

Loos, R. et al. 2008 Laboratory intercomparison study for the analysis of nonylphenol and octylphenol in river water. Trends Anal. Chem. 27, 89-95. (doi:10.1016/j.trac.2007. 10.011)

Loos, R. et al. 2009 EU-wide survey of polar organic persistent pollutants in European river waters. Environ. Pollut. 157, 561-568. (doi:10.1016/j.envpol.2008.09.020)

Maki, H., Masuda, N., Fujiwara, Y., Ike, M. \& Fujita, M. 1994 Degradation of alkylphenol ethoxylates by Pseudomonas sp. strain TR01. Appl. Environ. Microbiol. 60, 2265-2271.

Marcomini, A. \& Giger, W. 1987 Simultaneous determination of linear alkylbenzenesulfonates, alkylphenol polyethoxylates and nonylphenol by high-performance liquid chromatography. Anal. Chem. 59, 1709-1715. (doi:10.1021/ac00140a027)

Martin, O. V. \& Voulvoulis, N. 2009 Sustainable risk management of emerging contaminants in municipal wastewaters. Phil. Trans. R. Soc. A 367, 3895-3922. (doi:10.1098/rsta.2009.0115)

McLeese, D. W., Zitko, V., Metcalfe, C. D. \& Sergeant, D. B. 1980 Lethality of aminocarb and the components of the aminocarb formulation to juvenile Atlantic salmon, marine invertebrates and a freshwater clam. Chemosphere 9, 79-82. (doi:10.1016/0045-6535(80)90092-2)

Montgomery-Brown, J. \& Reinhard, M. 2003 Occurrence and behavior of alkylphenol polyethoxylates in the environment. Environ. Eng. Sci. 20, 471-486. (doi:10.1089/109287503 $768335940)$

Montgomery-Brown, J., Li, Y. M., Ding, W. H., Mong, G. M., Campbell, J. A. \& Reinhard, M. 2008 NP1EC degradation pathways under oxic and microxic conditions. Environ. Sci. Technol. 42, 6409-6414. (doi:10.1021/es702561t)

Patterson, S. J., Scott, C. C. \& Tucker, K. B. E. 1967 Nonionic detergent degradation. I. Thin-layer chromatography and foaming properties of alcohol polyethoxylates. J. Am. Oil Chem. Soc. 44, 407-412. (doi:10.1007/BF02666780)

Patterson, S. J., Scott, C. C. \& Tucker, K. B. E. 1968 Nonionic detergent degradation. II. Thinlayer chromatography and foaming properties of alkyl phenol polyethoxylates. J. Am. Oil Chem. Soc. 45, 528-532. (doi:10.1007/BF02541342)

Patterson, S. J., Scott, C. C. \& Tucker, K. B. E. 1970 Nonionic detergent degradation. III. Initial mechanism of degradation. J. Am. Oil Chem. Soc. 47, 37-41. (doi:10.1007/BF02541454)

Potter, T. L., Simmons, K., Wu, J., Sanchez-Olvera, M., Kostecki, P. \& Calabrese, E. 1999 Static die-away of a nonylphenol ethoxylate surfactant in estuarine water samples. Environ. Sci. Technol. 33, 113-118. (doi:10.1021/es9804464)

Preuss, T. G., Gehrhardt, J., Schirmer, K., Coors, A., Rubach, M., Russ, A., Jones, P. D., Giesy, J. P. \& Ratte, H. T. 2006 Nonylphenol isomers differ in estrogenic activity. Environ. Sci. Technol. 40, 5147-5153. (doi:10.1021/es060709r)

Reemtsma, T., Weiss, S., Mueller, J., Petrovic, M., Gonzalez, S., Barceló, D., Ventura, F. \& Knepper, T. P. 2006 Polar pollutants entry into the water cycle by municipal wastewater: a European perspective. Environ. Sci. Technol. 40, 5451-5458. (doi:10.1021/es060908a)

Rudling, L. \& Solyom, P. 1974 Investigation of biodegradability of branched nonyl phenol ethoxylates. Water Res. 8, 115-119. (doi:10.1016/0043-1354(74)90136-5)

Soares, A., Guieysse, B., Jefferson, B., Cartmell, E. \& Lester, J. N. 2008 Nonylphenol in the environment: a critical review on occurrence, fate, toxicity and treatment in wastewaters. Environ. Int. 34, 1033-1049. (doi:10.1016/j.envint.2008.01.004)

Shioji, H., Tsunoi, S., Kobayashi, Y., Shigemori, T., Ike, M., Fujita, M., Miyaji, Y. \& Tanaka, M. 2006 Estrogenic activity of branched 4-nonylphenol isomers examined by yeast two-hybrid assay. J. Health Sci. 52, 132-141. (doi:10.1248/jhs.52.132)

Soto, A. M., Justicia, H., Wray, J. W. \& Sonnenschein, C. 1991 -Nonylphenol: an estrogenic xenobiotic released from 'modified' polystyrene. Environ. Health Perspect. 92, $167-173$. 
Staples, C. A., Klecka, G. M., Naylor, C. G. \& Losey, B. S. 2008 C8- and C9-alkylphenols and ethoxylates: I. Identity, physical characterization, and biodegradation pathways analysis. Human Ecol. Risk Assess. 14, 1007-1024.

Stephanou, E. \& Giger, W. 1982 Persistent organic chemicals in sewage effluents. 2. Quantitative determinations of nonylphenols and nonylphenol ethoxylates by glass capillary gas chromatography. Environ. Sci. Technol. 16, 800-805. (doi:10.1021/es00105a014)

Sumpter, J. P. \& Johnson, A. C. 2008 Reflections on endocrine disruption in the aquatic environment: from known knowns to unknown unknowns (and many things in between). J. Environ. Mon. 10, 1476-1485. (doi:10.1039/b815741n)

Tanghe, T., Dhooge, W. \& Verstraete, W. 1999 Isolation of a bacterial strain able to degrade branched nonylphenol. Appl. Environ. Microbiol. 65, 746-751.

Tanghe, T., Dhooge, W. \& Verstraete, W. 2000 Formation of the metabolic intermediate 2,4,4,trimethyl-2-pentanol during incubation of a Sphingomonas sp. strain with the xeno-estrogenic octylphenol. Biodegradation 11, 11-19. (doi:10.1023/A:1026518727690)

Topp, E. \& Starratt, A. 2000 Rapid mineralization of the endocrine-disrupting chemical 4nonylphenol in soil. Environ. Toxicol. Chem. 19, 313-318. (doi:10.1897/1551-5028(2000)019 $<0313$ :RMOTED $>2.3 . \mathrm{CO} ; 2)$

Voutsa, D., Hartmann, P., Schaffner, C. \& Giger, W. 2006 Benzotriazoles, alkylphenols and bisphenol A in municipal wastewaters and in the Glatt River, Switzerland. Environ. Sci. Pollut. Res. 13, 333-341. (doi:10.1065/espr2006.01.295)

Wheeler, T. F., Heim, J. R., LaTorre, M. R. \& Janes, A. B. 1997 Mass spectral characterization of $p$-nonylphenol isomers using high-resolution capillary GC-MS. J. Chromatogr. Sci. 35, 19-30.

Wettstein, F. E. 2004 Auftreten und Verhalten von Nonylphenoxyessigsäure und weiteren Nonylphenolverbindungen in der Abwasserreinigung (in German). PhD thesis, ETH no. 15315, Zürich. [In German.] See http://e-collection.ethbib.ethz.ch/view/eth:27682.

Wild, D. \& Reinhard, M. 1999 Biodegradation residual of 4-octylphenoxyacetic acid in laboratory columns under groundwater recharge conditions. Environ. Sci. Technol. 33, 4422-4426. (doi:10.1021/es990295k) 